\title{
ANN based directional relaying scheme for protection of Korba-Bhilai transmission line of Chhattisgarh state
}

\author{
Anamika Yadav*, Yajnaseni Dash and V. Ashok
}

\begin{abstract}
As it is crucial to protect the transmission line from inevitable faults consequences, intelligent scheme must be employed for immediate fault detection and classification. The application of Artificial Neural Network (ANN) to detect the fault, identify it's section, and classify the fault on transmission lines with improved zone reach setting is presented in this article. The fundamental voltage and current magnitudes obtained through Discrete Fourier Transform (DFT) are specified as the inputs to the ANN. The relay is placed at section-2 which is the prime section to be protected. The ANN was trained and tested using diverse fault datasets; obtained from the simulation of different fault scenarios like different types of fault at varying fault inception angles, fault locations and fault resistances in a 400 kV, 216 km power transmission network of CSEB between Korba-Bhilai of Chhattisgarh state using MATLAB. The simulation outcomes illustrated that the entire shunt faults including forward and reverse fault, it's section and phase can be accurately identified within a half cycle time. The advantage of this scheme is to provide a major protection up to $99.5 \%$ of total line length using single end data and furthermore backup protection to the forward and reverse line sections. This routine protection system is properly discriminatory, rapid, robust, enormously reliable and incredibly responsive to isolate targeted fault.
\end{abstract}

Keywords: Artificial neural network, Fault classification, Fault detection, Fault direction estimation, Section identification

\section{Introduction}

As electric power system encompasses comprehensive interacting elements, there is a chance of occurring faults or unwanted short circuit conditions for all time. The flow of heavy currents due to short circuits causes damage to the equipments and other elements of power system [1]. Precise differentiation of faults and exact indication of fault type are the two key aspects for protecting the transmission line from various disturbances, faults and their consequences. Distance relay is one of the universal short circuit protection schemes in a transmission line which performs both primary and backup protection. Primary protection is as quick as possible with no time delay whereas back up protection is operational merely if primary relay fails. Various protecting zones are provided through distance relay based on the percentages of line impedances. The conventional distance relaying scheme usually provide protection to

\footnotetext{
* Correspondence: ayadav.ele@nitrr.ac.in

National Institute of Technology Raipur, Raipur, Chhattisgarh, India
}

only $80 \%$ of the line in Zone 1 , Zone 2 covers $120 \%$ of line and Zone 3 is set to cover the longest remote line. It is set up to operate with a twice time delay of Zone 1. Performance degradation occurs due to several circumstances like fault-path resistance, remote in-feed currents, and shunt capacitance [2,3].

Easy identification of the fault which might have been occurred in the transmission line can be achieved by an intelligent expert like ANN [4]. Diverse protecting mechanisms of transmission lines have been proposed earlier to detect and classify fault utilizing high frequency noise generated by fault and NNs [5], initial current travelling wave technique [6], wavelet transform [7], wavelet fuzzy combined approach [8], high speed protective relaying using ANN architecture and digital signal processing concepts. [9], modular yet integrated approach using modified Kohonen-type neural network [10], combined supervised and unsupervised neural network with ISODATA clustering algorithm [11], RBF NN with OLS learning method [12] and Combined fuzzy neural network [13-16] wavelet 
analysis and ANN [17-19], ANN Approach [20-25]. However these techniques did not identify the fault direction and section. Besides there are other techniques developed for fault detection and location using ANNs [26-29], Thevenin equivalent impedance and compensation factor [30], Clarke Concordia transformation, eigen value approach and NN [31], Kohonen network approach [32], Radial basis neural network [33, 34] and synchronized phasor measurement units (PMU) [35, 36]. However these techniques did not identify the fault type, fault direction and the faulty section. In some of the ANN based directional relaying techniques the fault types and the fault phases haven't been classified [37-39].

Presence of variety of intelligent techniques available for protecting the transmission line is still having certain issues which limit their applicability. This paper primarily aims to develop an efficient protection technique based on ANN with improved first zone reach setting and detection of fault is accomplished within half cycle of time. Thus, this paper has two key objectives: firstly to detects and classifies the fault and secondly to identify the zone of fault and the direction (whether it is forward or reverse fault). Effect of variation in different fault parameter like fault types, locations, inception angles, resistances were also exemplified here. As in this scheme, only single end data used, so there is no need of communicating link for remote end data.

\section{Power system under study}

An existing $400 \mathrm{kV}$ transmission line network of Chhattisgarh linking two utilities NTPC and CSEB has been considered. The power system network has two line sections of total length $216 \mathrm{~km}$ (NTPC, Korba 17 km- CSEB, Korba West -199 km- Khedamara, Bhilai). The power system network of Chhattisgarh State Electricity Board (CSEB) under study consist of $400 \mathrm{kV}, 50 \mathrm{~Hz}$ single circuit three phase transmission line of length $216 \mathrm{~km}$ as shown in single line diagram in Fig. 1. At Bus-1, four generating station of $500 \mathrm{MW}$ and three generating station of $210 \mathrm{MW}$ of NTPC Korba are connected which transfers power to BhilaiKhedamara $400 \mathrm{kV}$ grid at bus B4. At bus-2, two generating station of CSEB Korba West of $210 \mathrm{MW}$ are connected through a $17 \mathrm{~km}$ transmission line. Thereafter the power is transferred through $199 \mathrm{~km}$ transmission line to Bhilai-Khedamara $400 \mathrm{kV}$ grid at bus-3. Another three phase source of $400 \mathrm{kV}, 50 \mathrm{~Hz}$ is connected to bus-3 for simulating the remote end infeed which also represents the thevenin equivalent source of the interconnected grid. The proposed relay is situated at bus-2, so that directional relaying principle can be employed by considering the section- 2 of $199 \mathrm{~km}$ length as primary section to be protected and section- 1 of $17 \mathrm{~km}$ length as reverse line section as seen by the relay. Various types of shunt faults were simulated using three phase fault breaker.

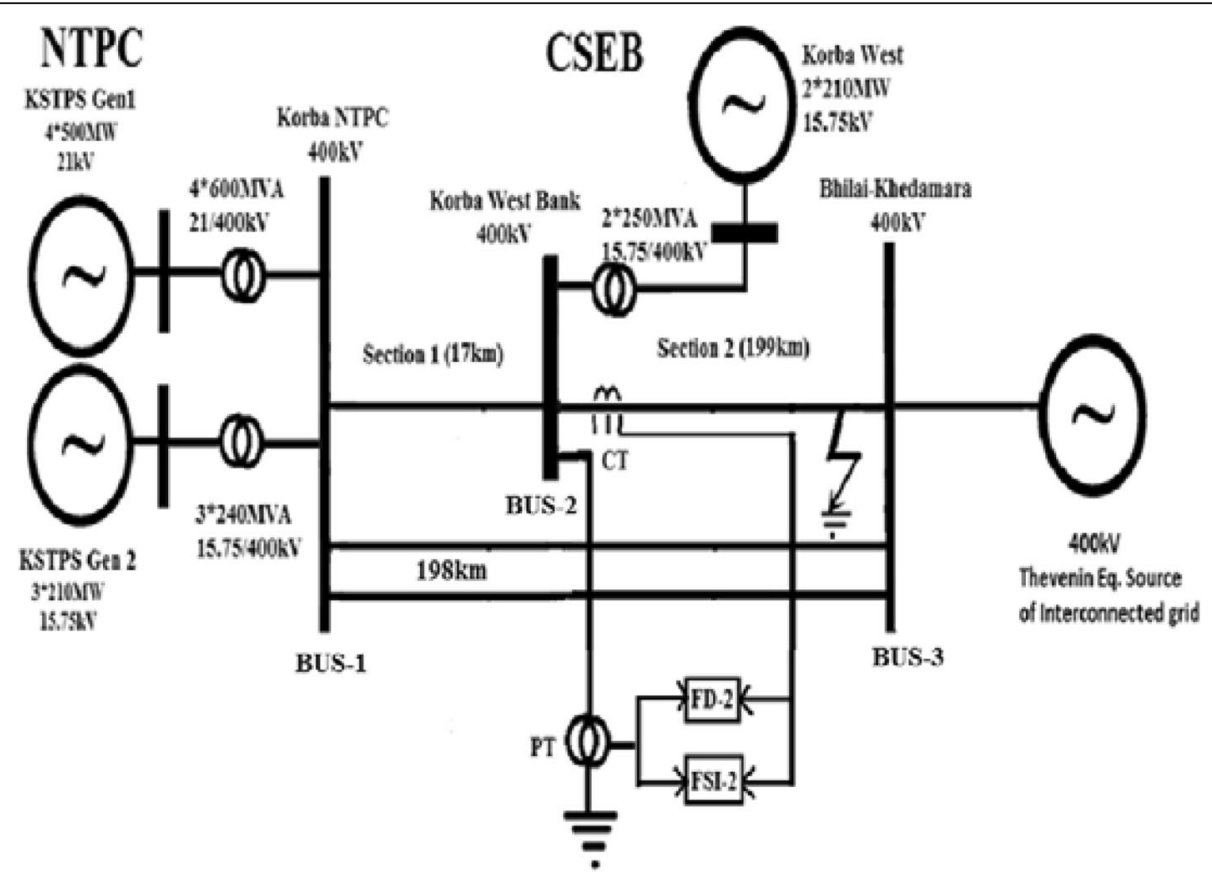

Fig. $1400 \mathrm{kV}$ transmission line network of Chhattisgarh linking two utilities NTPC and CSEB 


\section{Methods}

\section{Proposed ANN based fault detector, section estimator} and fault classifier

The proposed scheme deals with protective relaying tasks including fault section estimation and classification. Two ANNs have been designed, one for classification and other for section estimation. With the help of these networks, detection and classification of all 10 shunt faults, its section/zone and direction can be assessed by the using merely one terminal data. The simulations were conducted concerning different power systems and fault conditions for representing the robustness of the proposed scheme. Performance evaluation of the current study has been carried out using the MATLAB software. A transmission line $(400 \mathrm{kV})$ of length $216 \mathrm{~km}$ sectionalized in two zones fed from both the ends as described in the previous section has been chosen for this work.

Various kinds of shunt faults which may occur in transmission line in each section are LG, LL, LLG and LLL. These faults were simulated in a preferred power system model developed by using MATLAB software. The 3-phase voltage and current were measured at bus-2. These signals were sampled at $1 \mathrm{kHz}$ and then passed through analog filter. The analog filter is a Butterworth low pass filter of order 2 with pass band edge frequency $(480 \mathrm{~Hz})$ for removing higher order harmonics from the signal. Later, one full cycle recursive DFT was used for calculating the fundamental components of voltage and current. Then these signals were normalized in range -1 to +1 and fed to ANN for training, testing and validation. The flow chart for proposed absolute protecting scheme based on ANN was presented in Fig. 2.

The design process of the ANN based relay goes through the following steps:

a) Selection of inputs and outputs for ANN.

b) Simulation of different fault cases to form training and test data sets.

c) Architecture and training of ANN with appropriate training data sets.

\section{Selection inputs and outputs for ANN}

The deviations of the computed voltages and currents signals in the time domain are extremely perceptible and specific under verity of fault circumstances. Designing a fast and reliable ANN based relay concerns about the variations of current and voltage signals before and after the incidence of fault. When faults occur, diverse frequency components of signals appear, and the DC magnitude is attenuated according to the progression of time. In addition, a number of non-fundamental

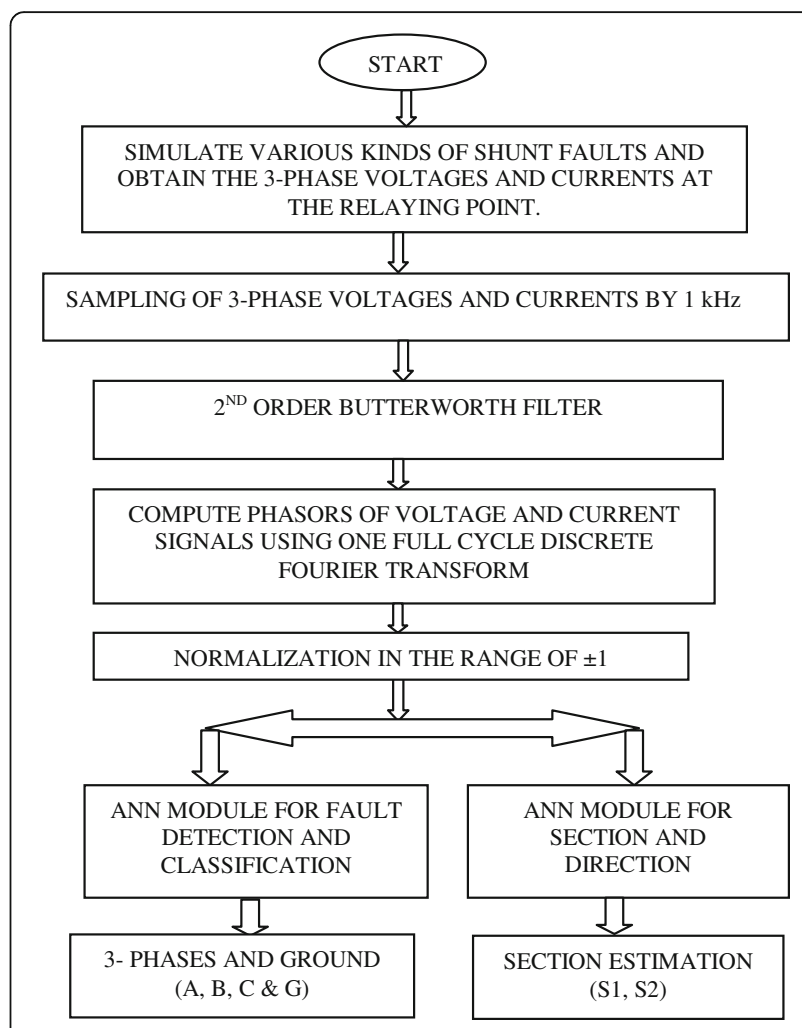

Fig. 2 Flow chart of the proposed protection scheme based on ANN

frequency components altered for different fault locations. As the performance of ANN depends upon the input and output characteristics, so, it is essential to preprocess and extract the useful features from the input data to train the ANN. The three phase instantaneous voltage and current signals were presented in Fig. 3 during AG fault at $5 \mathrm{~km}$ in Section 2 at $61 \mathrm{~ms}$ time with fault resistance $0.001 \Omega$. After $61 \mathrm{~ms}$ time, the faulty phase current starts increasing and voltage signal starts decreasing in magnitude. Figure 4 shows the fundamental components of voltage and current signals after preprocessing with DFT.

The inputs to the network were selected as the magnitudes of the fundamental components $(50 \mathrm{~Hz})$ of 3 phase voltages and currents assessed at the relay location at single end of the line. Therefore, the total inputs to ANN to detect \& classify fault, and estimate fault sections are six as presented in Eq. (1). Post fault samples (10) of fundamental components of 3-phase voltage and current signals were extracted for forming the input matrix of ANN training as shown in Eq. (2).

$$
X=\left[V_{a f}, V_{b f}, V_{c f}, I_{a f}, I_{b f}, I_{c f}\right]
$$



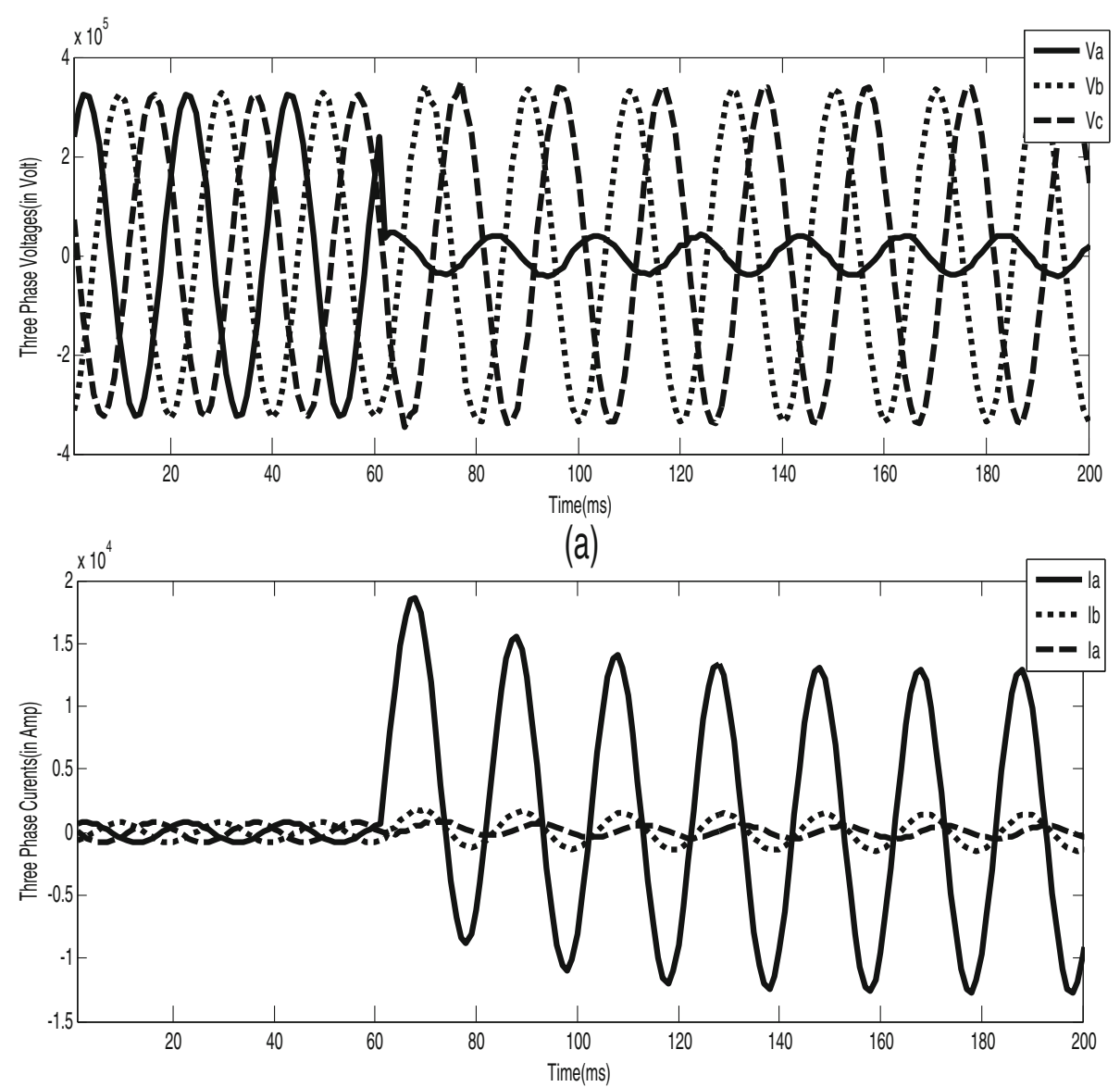

(b)

Fig. 3 a, b Three phase instantaneous voltages and currents during an AG fault at $5 \mathrm{~km}$ in Section 2 at 61 ms with Rf $=0.001 \Omega$ respectively

$$
\begin{aligned}
& X=\left[\begin{array}{c}
V_{p f} \\
I_{p f}
\end{array}\right]
\end{aligned}
$$

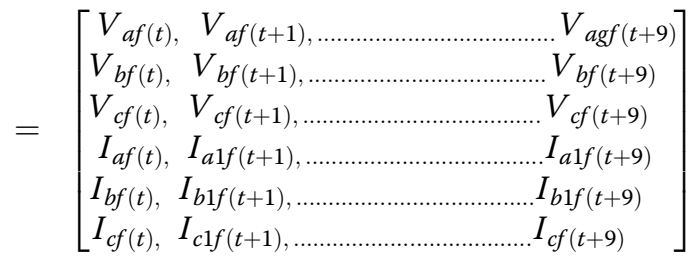

There are 2 outputs corresponding to the two sections $\mathrm{S} 1$ and $\mathrm{S} 2$ in the fault section identification module of ANN. Thus, the faulty section can be identified as shown in Eq. (3). Output of each section is ' 0 ' if no fault or ' 1 ' if there is fault.

$$
Y 1=[S 1, S 2]
$$

In addition, the fault type as well as the faulty phase selection was determined by the fault classification module of ANN. Fault classification module has two networks one for fault phase identification and one for ground identification. Thus, the 3 - phases and neutral were considered as outputs given by the network for determining the faulty phase $(\mathrm{A}, \mathrm{B}, \mathrm{C}$ and $\mathrm{G}$ ) presented in the fault loop. Depending on the fault kind occurring in the system, outputs must be '0' or ' 1 '. Hence the fault classification outputs of network were shown in Eqs. (4) and (5)

$$
\begin{aligned}
Y 2 & =[A, B, C] \\
Y 3 & =[G]
\end{aligned}
$$

\section{Simulation of different fault cases to form training and test data set}

Various fault parameters were varied for generating different fault cases. The 3-phase currents and voltages measured at single end of the single circuit line were used to compute DFT coefficients of the signal in 

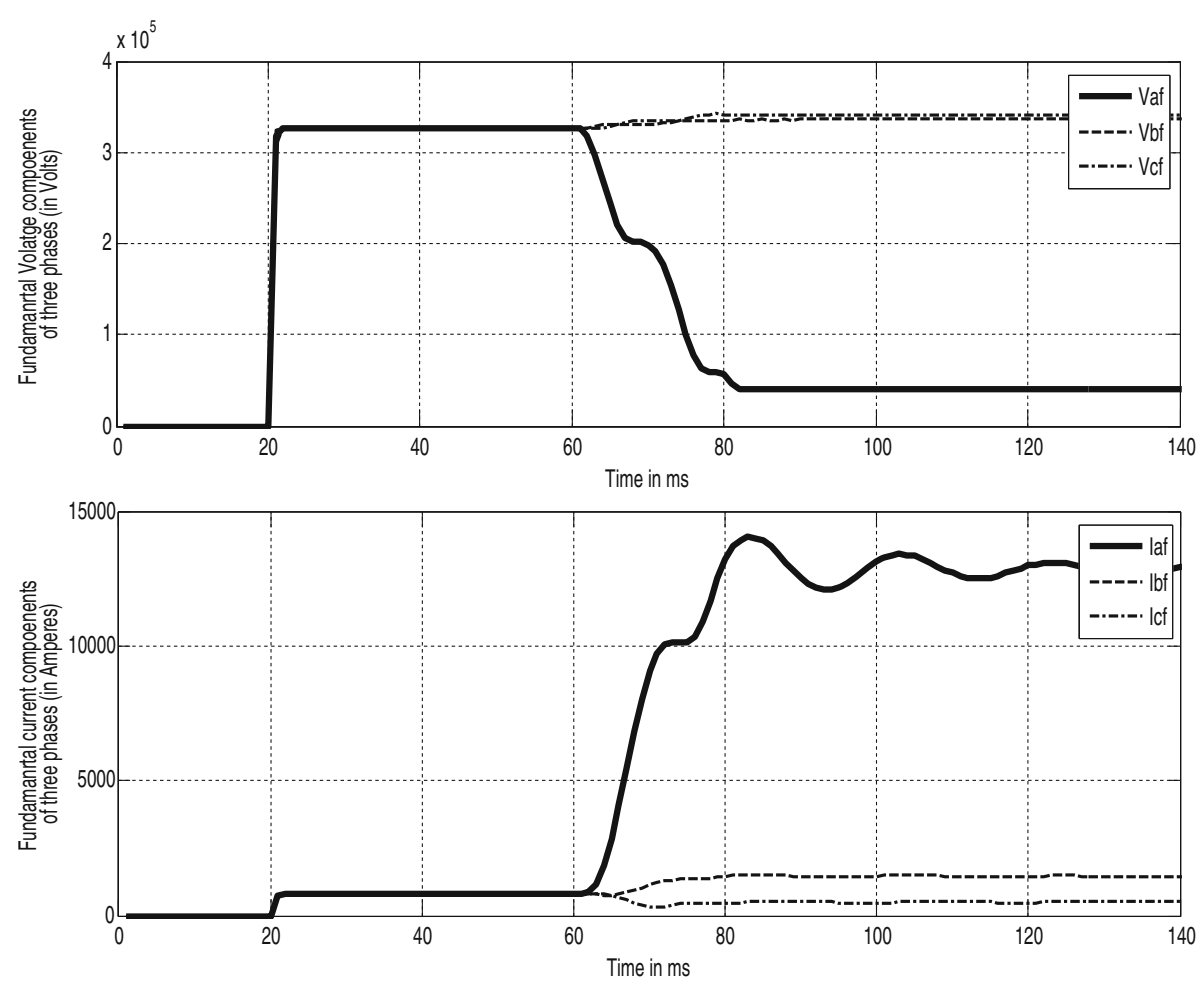

Fig. 4 Fundamental components of 3-phase voltage and current during an AG fault at $5 \mathrm{~km}$ in Section 2 at $61 \mathrm{~ms}$ with $\mathrm{Rf}=0.001 \Omega$

MATLAB. DFT coefficients were applied as input to feed forward NN with Levenberg- Marquardt (LM) training algorithm to discriminate the fault, classify and also to identify the zone of faults. A large variety of fault cases have been studied using different parameters like fault inception angle/time, location, resistance, ground resistance, and fault types (LG, LLG, LL and LLL). Different fault parameter variation employed for training and testing the ANN was presented in Table 1. Fault case studies carried out to train the neural network involves 10 (fault type) $\times 23$ (3 fault locations for section 1 and 20 for section 2$) \times 1$ (fault inception angle) $\times 2$ (fault resistance) $=460$ cases. The total numbers of samples utilized to train the neural network are 5082 to identify faulty section and 4089 for fault classification \& phase identification and 4085 for ground identification.

Total number of fault cases for testing the neural network is 1 (fault section-2) $\times 10$ (fault type) $\times 20$ (fault locations $) \times 1$ (fault inception angle $) \times(10$ fault resistance for 6 type of LG and LLG fault + 2 fault resistance for 4 types of LL and LLL fault) $=1360$ cases. Seven different fault locations in step of 10 such as $(1,11,21 \ldots . .191 ; 2$,

Table 1 Fault cases in training and testing purpose

\begin{tabular}{|c|c|c|}
\hline Parameters & Training Data & Testing Data \\
\hline Fault sections & Section-1 (S1) and Section-2 (S2) & section-1 (S1) and section-2 (S2) \\
\hline Fault type & $\begin{array}{l}\text { LG (AG, BG, CG), LLG (ABG, BCG, ACG), LL (AB, BC, CA), } \\
\operatorname{LLL}(A B C)\end{array}$ & $\begin{array}{l}\text { LG (AG, BG, CG), LLG (ABG, BCG, ACG), LL (AB, BC, CA), } \\
\operatorname{LLL}(A B C)\end{array}$ \\
\hline $\begin{array}{l}\text { Fault location: } \\
\text { FL in }(\mathrm{km})\end{array}$ & $\begin{array}{l}\text { Section } 1 \text { (5,10 and } 15=3 \text { locations) and Section } 2 \\
(5,15,25, \ldots 195=20 \text { locations }) \\
\text { Total locations }=23\end{array}$ & $\begin{array}{l}\text { Different fault location between } 1-17 \mathrm{~km} \text { for section-1 } \\
\text { and } 1-199 \mathrm{~km} \text { for section- } 2 \text {. }\end{array}$ \\
\hline $\begin{array}{l}\text { Fault inception angle: } \\
\Phi \mathrm{i} \text { in }\left(^{\circ}\right)\end{array}$ & 0 & $0,45,90,135,180,225,270,315$ \\
\hline \multirow[t]{2}{*}{$\begin{array}{l}\text { Fault Resistance: } \\
\mathrm{R}_{\mathrm{f}} \text { in }(\Omega)\end{array}$} & 0,10 for phase faults and 0,100 ohms for ground faults & $\begin{array}{l}0,10 \ldots \ldots 100=10 \text { fault resistance for } 6 \text { type of } L G \\
\text { and } L L G \text { fault }+2 \text { fault resistance for } 4 \text { types of } L L \text { and LLL fault }\end{array}$ \\
\hline & Total fault cases $=460$ cases & Total fault cases $=328($ section- 1$)+9520($ section -2$)=9848$ \\
\hline
\end{tabular}


$12,22 \ldots .192 ; 3,13,33 \ldots 193 ; 4,14,24 \ldots 194 ; 6,16,26 \ldots$ $196 ; 7,17,27 \ldots 197 ; 8,18,28 \ldots 198)$ were taken into consideration. So, total numbers of cases are $1360 \times 7=$ 9520 and thereafter 26 samples of each fault cases has been extracted which comes out to be $9520 \times 26=$ 247520 samples and 70 no fault samples has been added to form total 247590 samples/testing data set which has been used for testing the network.

\section{Architecture and training of ANN with appropriate training data sets}

After selecting the inputs and outputs for ANN, the number of layers and the number of neurons per layer were determined. Neuron numbers in hidden layer was decided by random investigation of $5,10, \ldots ., 20$ neurons. Then the transfer function was decided from the commonly used functions for instance, logsig, tansig, purelin, satlin etc. Different variations of fault scenarios were considered throughout the training process to make the ANN to learn accurately the fundamental problem and can respond accordingly. All the 10 types of shunt faults including LG, LLG, LL, and LLL have been simulated in the two sections of line (between $0-100 \%$ of line length) at 328 different fault locations with varied fault resistance $(0,20,40,60,80$ and $100 \Omega)$ and fault inception angles $\left(0\right.$ to $\left.360^{\circ}\right)$. The overall fault cases utilized for training and testing are 1380 and 9848 respectively. Several networks with a number of neurons in their hidden layer were trained with Levenberg-Marquardt (LM) algorithm. From earlier studies, it was observed that the ANNs trained with the LM algorithm bestow improved outcomes as compared to the outcomes of the ANNs trained with the Back propagation (BP) algorithm. The LM, a nonlinear least square algorithm utilized for the learning purpose of multilayer neurons. Therefore, the LM training algorithm is used for this purpose. Total fault samples taken for section identification are 5082. It has been observed that the neural network was having 6 neurons in input, 20 neurons in $1^{\text {st }}$ hidden layer, 20 neurons in $2^{\text {nd }}$ hidden layer and 1 neuron in output layer all comprising of "tansig" activation function for ANN based fault detector (6-20-20-2) can able to minimize the mean square error (mse) to an ultimate value of 0.00000989 . Total fault samples taken for fault phase identification are 4089 and corresponding to the input samples target is assigned. ANN network is trained using 2 hidden layers with 20 neurons in each layer as like as fault section identification training network. In the learning process of the network, the mse reduces in 94 cycles to 0.000000968 . Total fault samples taken for ground identification are 4085. ANN network is trained using 2 hidden layers with 12 neurons in $1^{\text {st }}$ layer and 10 neurons in $2^{\text {nd }}$ layer. Here hyperbolic tangent sigmoid transfer function (tansig) and Levenberg-Marquardt algorithm were used. This network with 2 hidden layers is able to minimize the mse to an ultimate value of 0.000000979. The learning approach converges fast and through learning the mse reduces in 56 cycles to 0.000000979 .

\section{Results and discussions}

There is necessity for testing of the ANN based fault section estimator and fault classifier/faulty phase identifier. This is required for identification of faults and variations in network parameters for which the network has not been trained earlier. Cases included in the validation data set are like faults nearer to protection zone boundary and high resistance faults. Testing of ANN was performed utilizing different types of faults like LG, LLG, LL and LLL in the two sections with different fault locations $\left(\mathrm{L}_{\mathrm{f}}=0-199 \mathrm{~km}\right.$ in section-2 and 1-17 in section-1), fault inception angles $\left(\Phi_{\mathrm{i}}=0-360^{\circ}\right)$ and fault resistance $\left(R_{\mathrm{f}}=0-100 \Omega\right)$. Table 2 shows the results based upon performance analysis of the whole scheme with respect to the percentage of correct answers and the detection time for various types of fault test cases. It is evident from Table 2 that percentage of accuracy and correct answers were high and the detection time was less than quarter cycle for most of the test cases in both the cases of fault detection/section estimation and fault classification modules. It was also less than half cycle for few cases only.

Evaluations of the proposed relay operation/fault detection time and reach setting were performed at faults near boundary in the 4.1 and 4.2 respectively. Proposed scheme was also verified using various faulted conditions like faults close to boundaries with high fault resistance, changeable faults inception angles. These test results were presented in following sub-sections.

Table 2 Detection time for fault section estimation and classification networks

\begin{tabular}{llll}
\hline ANN Network & Test Cases & Detection Time (ms) & Accuracy (correct answers) \\
\hline Section estimation network & $82 \%$ & Less than quarter cycle & $100 \%$ (277137 cases) \\
& $18 \%$ & Less than half cycle & \\
Fault classification network & $80 \%$ & Less than quarter cycle & $99.6 \%$ (247590 cases) \\
& $20 \%$ & Less than half cycle & \\
\hline
\end{tabular}




\section{Performance analysis}

Evaluation of relay performance was done for ANN based fault detector, section estimator and classifier utilizing different fault cases based upon varied resistances, inception angles, types and locations. Performance of the scheme will be analyzed in terms of fault detection time and fault detection accuracy. Different fault resistances such as $0 \Omega$, $20 \Omega, 40 \Omega, 60 \Omega$ and $80 \Omega$ were taken into consideration for identifying the fault, the faulty section and classification of fault. During a relay design, the key consideration was that its operation time should be less than a cycle time. In other schemes of conventional digital distance relaying, operating time is near about one cycle. In the present study we have considered $A B C$ fault at $160 \mathrm{~km}$ away from bus- 2 in section- 2 with $R_{f}=0 \Omega, \Phi_{i}=0^{\circ}$ at $60 \mathrm{~ms}$ for evaluation of proposed relay operating time. Figure 5 depicts waveform related to output of ANN based fault section estimator for S1 and S2.

Outputs were low (zero) up to $60 \mathrm{~ms}$ in both the sections S1 and S2 which show that there is no occurrence of fault. The output of Output S2 of ANN based section estimator, after the occurrence $\mathrm{ABC}$ fault at $60 \mathrm{~ms}$ goes high (1) at $63 \mathrm{~ms}$ time in comparison with other output S1, which remained low (0) and unaffected. Thus the fault is in section-2. The operating time of relay can be calculated as follows:

\section{Fault Inception time $=60 \mathrm{~ms}$ \\ Fault detection time $=63 \mathrm{~ms}$}

Hence time of operation $=(63-60) \mathrm{ms}$
Figure 6 depicts the output of ANN based fault classifier and faulty phase identifier during $A B G$ fault at $180 \mathrm{~km}$ in Section-2 with $\mathrm{Rf}=0 \Omega, \phi \mathrm{i}=0^{\circ}$ at $60 \mathrm{~ms}$. Fault locations of forward section are from $181 \mathrm{~km}$ to $198 \mathrm{~km}$ with $0^{\circ}$ inception angles where fault classification takes less than a cycle of time as presented in Table 3. In Fig. 7, the output of ANN based phase identifier during BG fault at $183 \mathrm{~km}$ in Section-2 with $\mathrm{R}_{\mathrm{f}}=20 \Omega, \phi \mathrm{i}=0^{\circ}$ at 60 ms represented.

It is worthwhile to mention here that, one full cycle recursive DFT has been used for estimating fundamental components of 3-phase currents and voltages in time domain. The increase and reduction in fundamental components of faulty phase currents and voltages respectively after fault inception at $60 \mathrm{~ms}$ can be detected by ANN. As a result of recursive DFT which computes the fundamental components values in time domain a continuous manner, the output of proposed ANN in corresponding faulty section rises to high output (1) at $63 \mathrm{~ms}$ as shown in Fig. 5.

Speed of the algorithm to detect the fault is less than quarter -half time, represents the response time of the algorithm given the test fault case input patterns to detect the fault i.e. transition of the output from no fault state (zero) to faulted state (one) after the initiation of the fault. Or in other word, quarter-half cycle samples of the voltages and currents are required to detect the fault. This speed does not account for the execution time of the simulation of the ANN algorithm using MATLAB/Simulink on a PC or workstation. Execution time of the simulation of the ANN algorithm will be affected by the computer tool i.e. either PC or workstation. Thus analysis in terms of the

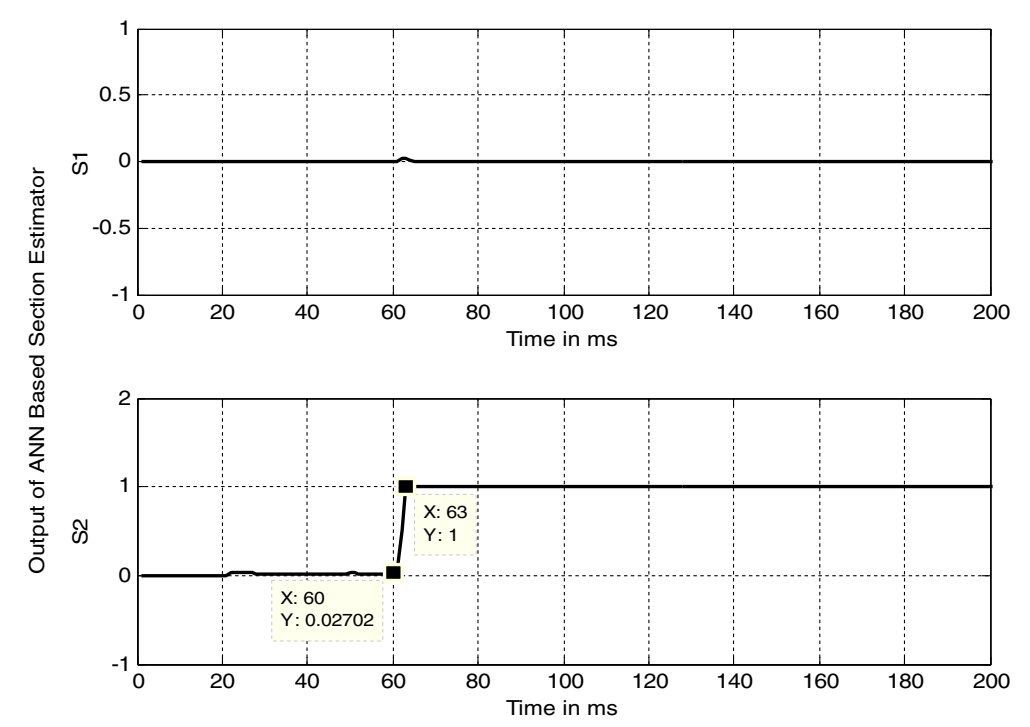

Fig. 5 Output of ANN based section estimator during $A B C$ fault at $160 \mathrm{~km}$ in Section-2 with $\mathrm{Rf}=0 \Omega, \phi i=00$ at 60 ms time 

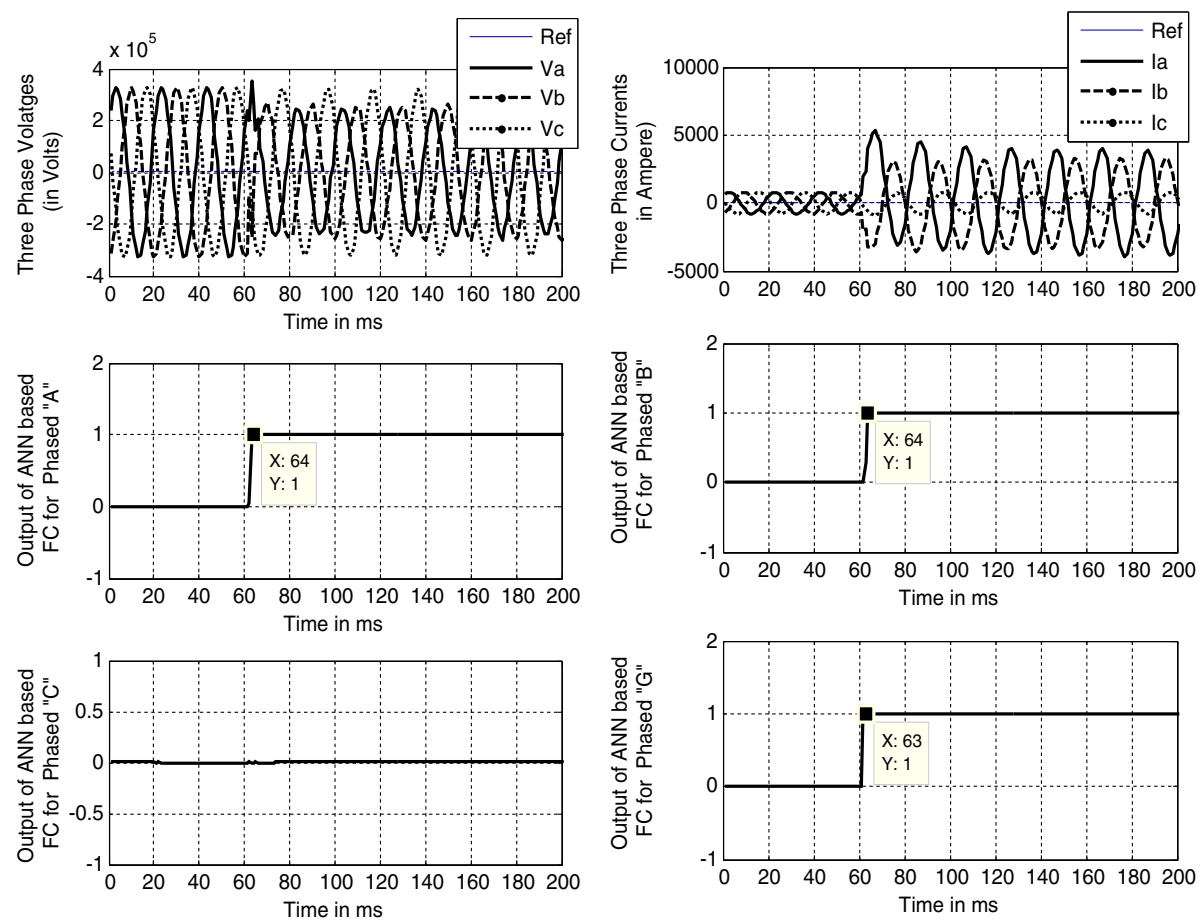

Fig. 6 Output of ANN based Fault Classifier during ABG fault at $180 \mathrm{~km}$ in Section-2 with $\mathrm{Rf}=0 \Omega, \phi i=00$ at 60 ms

Table 3 Response for LL, LLL, LG, LLG faults with $\phi i=0^{\circ}$ at $60 \mathrm{~ms}$ and variable fault resistance

\begin{tabular}{|c|c|c|c|c|c|c|c|}
\hline \multirow[t]{2}{*}{ Fault type } & \multirow{2}{*}{$\begin{array}{l}\text { Fault } \\
\text { resistance }\end{array}$} & \multirow{2}{*}{$\begin{array}{l}\text { Fault } \\
\text { location }\end{array}$} & \multicolumn{4}{|c|}{ Fault phase identification time } & \multirow{2}{*}{$\begin{array}{l}\text { Fault section } \\
\text { identification time }\end{array}$} \\
\hline & & & $\bar{A}$ & $B$ & $C$ & $G$ & \\
\hline$A B C$ & 0 & 181 & 4 & 4 & 8 & - & 3 \\
\hline$A C$ & 10 & 182 & 4 & - & 6 & - & 3 \\
\hline BG & 20 & 183 & - & 5 & - & 2 & 4 \\
\hline$A B G$ & 40 & 184 & 4 & 8 & - & 2 & 3 \\
\hline ACG & 60 & 185 & 5 & - & 8 & 2 & 3 \\
\hline $\mathrm{BCG}$ & 80 & 186 & - & 10 & 9 & 2 & 7 \\
\hline$B C$ & 0 & 187 & - & 4 & 10 & - & 4 \\
\hline$B C$ & 10 & 188 & - & 5 & 10 & - & 3 \\
\hline$A B$ & 10 & 189 & 4 & 5 & - & - & 3 \\
\hline$C G$ & 20 & 190 & - & - & 7 & 4 & 8 \\
\hline$A B G$ & 40 & 191 & 4 & 9 & - & 5 & 3 \\
\hline ACG & 60 & 192 & 5 & - & 8 & 4 & 3 \\
\hline $\mathrm{BCG}$ & 80 & 193 & - & 10 & 10 & 6 & 7 \\
\hline$A B C$ & 0 & 194 & 4 & 4 & 8 & - & 3 \\
\hline$A C$ & 10 & 195 & 4 & - & 6 & - & 4 \\
\hline$A G$ & 20 & 196 & 4 & - & - & 10 & 3 \\
\hline$A B G$ & 40 & 197 & 4 & 10 & - & 5 & 3 \\
\hline ACG & 60 & 198 & 6 & - & 9 & 4 & 4 \\
\hline
\end{tabular}



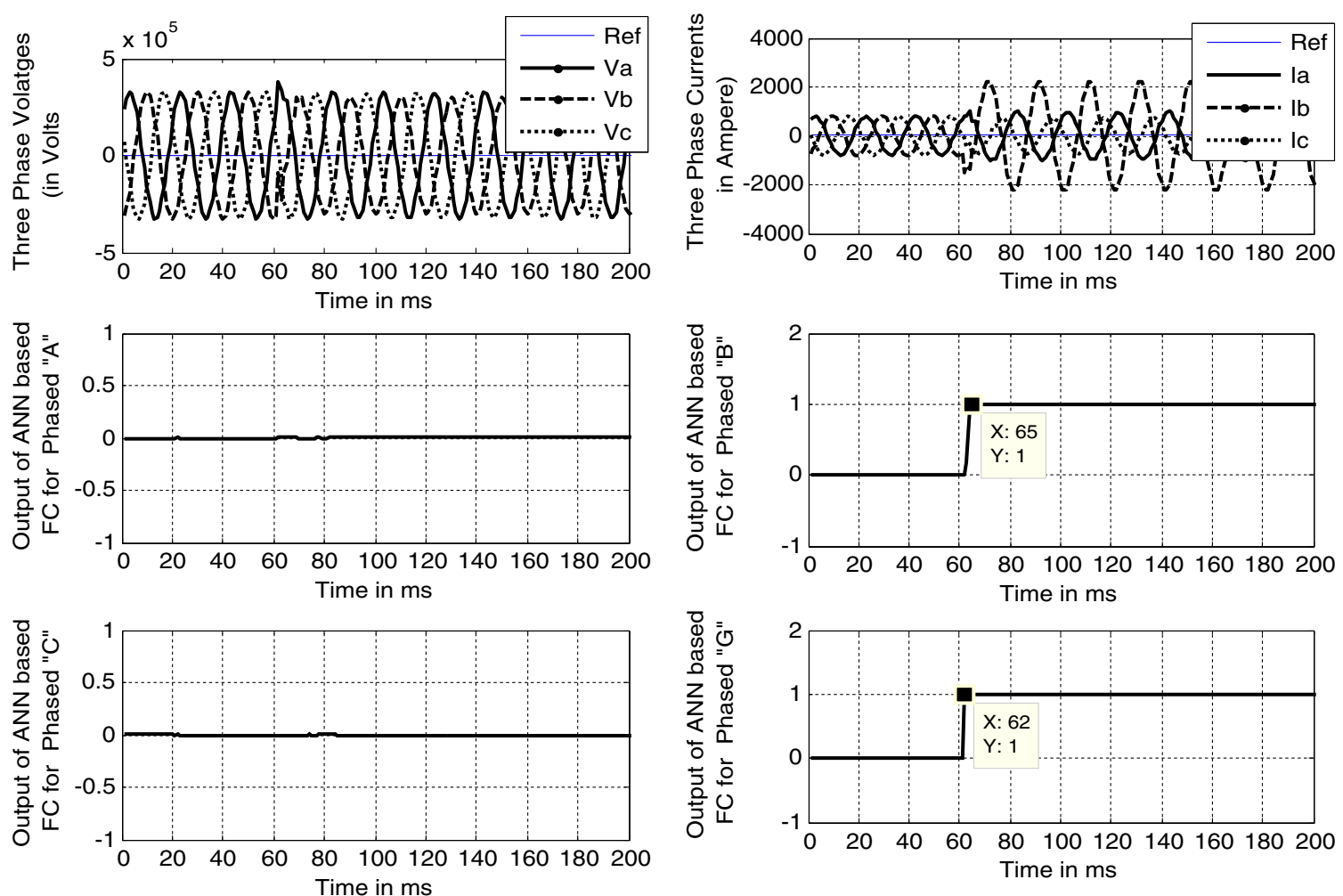

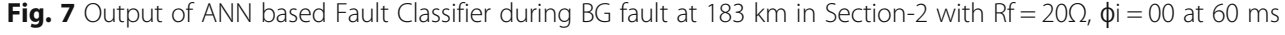

execution time of the proposed algorithm has been carried out in a PC of with $2 \mathrm{~GB}$ RAM and Intel(R) Core(TM), i7-3770 CPU, 3.4 GHz, 32bit processor and HP Z230 workstation with 4GB RAM and Intel(R) Xeon (R), CPU E3-1240 V3, 3.4 GHz, 64 bit processor. The average execution time for the simulation of the ANN algorithm implemented using MATLAB/Simulink on a PC and workstation is found to be $20.741 \mathrm{~ms}$ and 16.9 ms respectively.

\section{Performance during far end boundary faults with high fault resistance}

In a conventional manner, the digital distance relay's first zone reach setting is typically set as $80 \%$ of line length.

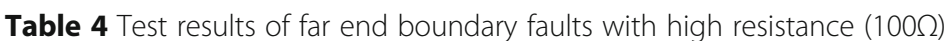

\begin{tabular}{|c|c|c|c|c|c|c|c|}
\hline \multirow[t]{2}{*}{ Fault type } & \multirow{2}{*}{$\begin{array}{l}\text { Fault } \\
\text { location }\end{array}$} & \multicolumn{2}{|c|}{ Fault section identification time } & \multicolumn{4}{|c|}{ Fault phase identification time } \\
\hline & & $\mathrm{S1}$ & S2 & A & B & $C$ & G \\
\hline AG & 180 & - & 3 & 5 & - & - & 2 \\
\hline BG & 182 & - & 9 & - & 10 & - & 2 \\
\hline CG & 184 & - & 10 & - & - & 9 & 2 \\
\hline$A B G$ & 186 & - & 3 & 6 & 10 & - & 2 \\
\hline BCG & 188 & - & 8 & - & 10 & 10 & 2 \\
\hline CAG & 190 & - & 4 & 7 & - & 10 & 4 \\
\hline AG & 192 & - & 4 & 7 & - & - & 5 \\
\hline BG & 194 & - & 10 & - & 10 & - & 4 \\
\hline CG & 196 & - & 11 & - & - & 10 & 5 \\
\hline ABG & 198 & - & 4 & 12 & 12 & - & 6 \\
\hline
\end{tabular}


Table 5 Test results for varying fault location with high fault

\begin{tabular}{|c|c|c|c|c|}
\hline \multirow[t]{2}{*}{ Fault type } & \multirow{2}{*}{$\begin{array}{l}\text { Fault } \\
\text { resistance }\end{array}$} & \multirow{2}{*}{$\begin{array}{l}\text { Fault } \\
\text { location }\end{array}$} & \multicolumn{2}{|c|}{ Fault section identification time } \\
\hline & & & $\overline{S 1}$ & $\mathrm{~S} 2$ \\
\hline \multirow[t]{5}{*}{$\overline{A G}$} & 100 & -1 & 3 & - \\
\hline & & -16 & 3 & - \\
\hline & & 1 & - & 2 \\
\hline & & 101 & - & 3 \\
\hline & & 198 & - & 4 \\
\hline \multirow[t]{5}{*}{$A B G$} & 100 & -4 & 3 & - \\
\hline & & -13 & 3 & - \\
\hline & & 33 & - & 3 \\
\hline & & 133 & - & 3 \\
\hline & & 170 & - & 3 \\
\hline \multirow[t]{5}{*}{ ACG } & 100 & -5 & 3 & - \\
\hline & & -12 & 3 & - \\
\hline & & 44 & - & 2 \\
\hline & & 144 & - & 3 \\
\hline & & 160 & - & 3 \\
\hline
\end{tabular}

This resulted in incapability for instant detection of faults close to remote end bus; however they were identified after some delay based on zone- 2 timings. Various types of faults with $R_{f}=100 \Omega$ have been simulated with changeable fault locations in step of $1 \mathrm{~km}$ between $180-198 \mathrm{~km}$ in section-2 for studying relay performance for faults adjacent to remote end bus with high fault resistance. Table 4 summarises the responses of the protection scheme for far end faults with high fault resistance, and Table 5 depicts the test results for varying fault location with high fault resistance. In most of the cases, the
Table 6 Performance in case of varying fault resistances

\begin{tabular}{|c|c|c|c|c|c|c|}
\hline \multirow{2}{*}{$\begin{array}{l}\text { Fault } \\
\text { type }\end{array}$} & \multirow{2}{*}{$\begin{array}{l}\text { Fault } \\
\text { location }\end{array}$} & \multirow{2}{*}{$\begin{array}{l}\text { Fault } \\
\text { resistance }\end{array}$} & \multicolumn{3}{|c|}{ Fault Phase identification time } & \multirow{2}{*}{$\begin{array}{l}\text { Detection } \\
\text { time of } \\
\text { forward } \\
\text { section }\end{array}$} \\
\hline & & & $A$ & C & G & \\
\hline \multirow[t]{7}{*}{$\overline{A G}$} & \multirow[t]{7}{*}{$40 \mathrm{~km}$} & 0 & 3 & - & 2 & 2 \\
\hline & & 10 & 3 & - & 3 & 2 \\
\hline & & 20 & 3 & - & 2 & 2 \\
\hline & & 40 & 3 & - & 2 & 2 \\
\hline & & 60 & 3 & - & 2 & 2 \\
\hline & & 80 & 3 & - & 2 & 2 \\
\hline & & 100 & 3 & - & 2 & 2 \\
\hline \multirow[t]{7}{*}{ ACG } & \multirow[t]{7}{*}{$120 \mathrm{~km}$} & 0 & 3 & 6 & 3 & 3 \\
\hline & & 10 & 3 & 6 & 3 & 3 \\
\hline & & 20 & 4 & 7 & 3 & 3 \\
\hline & & 40 & 3 & 7 & 3 & 3 \\
\hline & & 60 & 4 & 7 & 3 & 3 \\
\hline & & 80 & 4 & 7 & 3 & 3 \\
\hline & & 100 & 4 & 7 & 3 & 3 \\
\hline
\end{tabular}

relay operation time is within half cycle time $(10 \mathrm{~ms})$, except in one case where it is $11 \mathrm{~ms}$. The farthest end fault case of ABG fault at $198 \mathrm{~km}$ from the relay location at bus- 2 with $R_{\mathrm{f}}=100 \Omega$ at $60 \mathrm{~ms}$ was represented graphically in Fig. 8. Hence, it is summarised that the reach of the relay is approximately $99.5 \%$ in the first zone. The proposed scheme could detect the forward faults and its zone within half cycle time in all the cases.

\section{Impact of fault resistance}

The current study based on fault classification and phase selection using ANN module was tested for

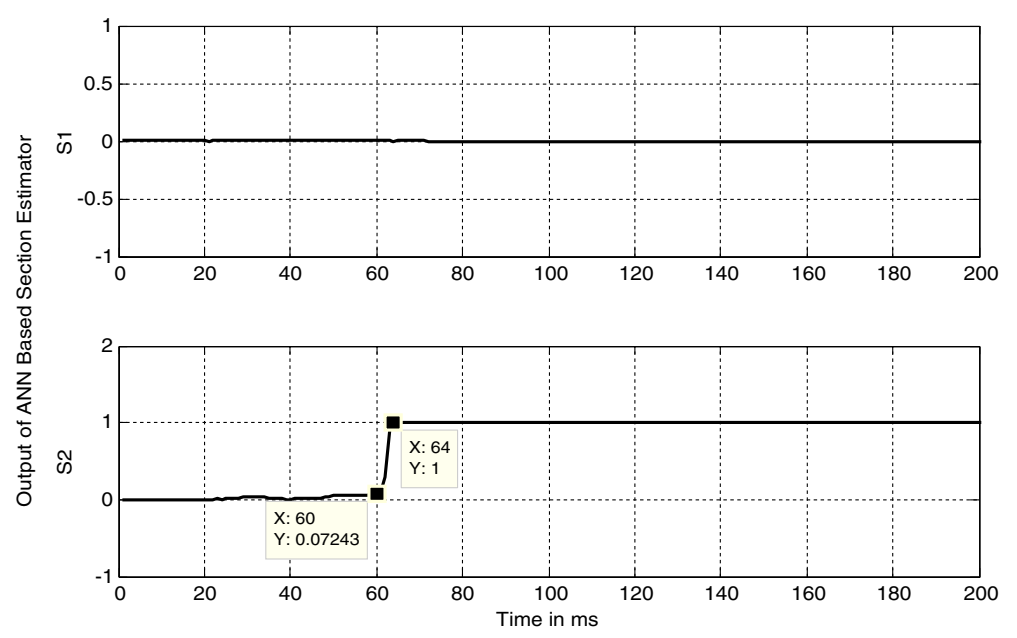

Fig. 8 Output of ANN based section estimator for ABG fault at $198 \mathrm{~km}$ from bus-2 in Section-2 with $R_{f}=100 \Omega, \phi i=0^{0}$ at 60 ms time 

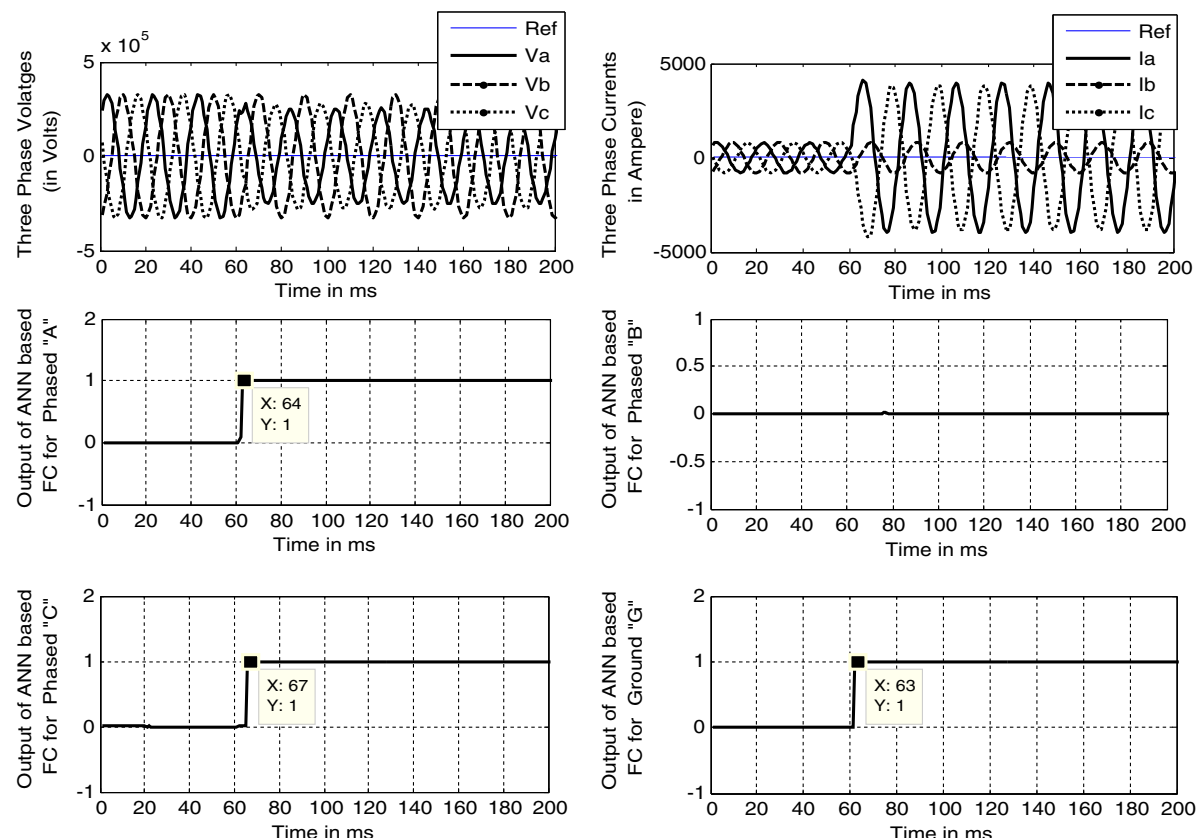

Fig. 9 Output of ANN based Fault Classifier during ACG fault at $120 \mathrm{~km}$ in Section-2 with $R_{f}=20 \Omega, \phi i=0^{0}$ at $60 \mathrm{~ms}$

different fault resistances. Different fault resistances such as $0 \Omega, 20 \Omega, 40 \Omega, 60 \Omega$ and $80 \Omega$ were taken into consideration for identifying the faulty phase and the type of fault and few test results for various fault resistances were demonstrated in Table 6 and Fig. 9 shows the Output of ANN based fault classifier during ACG fault at $120 \mathrm{~km}$ in Section-2 with $R_{\mathrm{f}}=20 \Omega$, $\phi \mathrm{i}=0^{0}$ at $60 \mathrm{~ms}$. First two plots of Fig. 9 shows the instantaneous current and voltage signals. Output of ANN based fault phase identifier become high in A, C phases and G after $64 \mathrm{~ms}, 67 \mathrm{~ms}$ and $63 \mathrm{~ms}$ time respectively. Thus the fault is classified as LLG after $7 \mathrm{~ms}$ from the fault inception time and the faulty phases are $\mathrm{A}, \mathrm{C}$ and $\mathrm{G}$.

Table 7 Performance in case of different fault inception angle

\begin{tabular}{|c|c|c|c|c|c|c|}
\hline \multirow[t]{2}{*}{ Fault type } & \multirow[t]{2}{*}{ Fault location } & \multirow{2}{*}{$\begin{array}{l}\text { Fault inception } \\
\text { angle }\end{array}$} & \multirow{2}{*}{$\begin{array}{l}\text { Detection time of } \\
\text { forward section }\end{array}$} & \multicolumn{3}{|c|}{ Fault phase identification time } \\
\hline & & & & A & B & G \\
\hline \multirow[t]{8}{*}{$A G$} & \multirow[t]{8}{*}{150} & 0 & 3 & 3 & - & 2 \\
\hline & & 45 & 2.5 & 3.5 & - & 3.5 \\
\hline & & 90 & 10 & 8 & - & 2 \\
\hline & & 135 & 4.5 & 5.5 & - & 3.5 \\
\hline & & 180 & 3 & 3 & - & 2 \\
\hline & & 225 & 2.5 & 3.5 & - & 3.5 \\
\hline & & 270 & 10 & 8 & - & 2 \\
\hline & & 315 & 4.5 & 5.5 & - & 3.5 \\
\hline \multirow[t]{8}{*}{$A B G$} & \multirow[t]{8}{*}{150} & 0 & 3 & 3 & 4 & 3 \\
\hline & & 45 & 2.5 & 3.5 & 9.5 & 1.5 \\
\hline & & 90 & 5 & 8 & 5 & 2 \\
\hline & & 135 & 3.5 & 5.5 & 3.5 & 4.5 \\
\hline & & 180 & 3 & 3 & 4 & 3 \\
\hline & & 225 & 2.5 & 3.5 & 9.5 & 1.5 \\
\hline & & 270 & 5 & 8 & 5 & 2 \\
\hline & & 315 & 3.5 & 5.5 & 3.5 & 4.5 \\
\hline
\end{tabular}




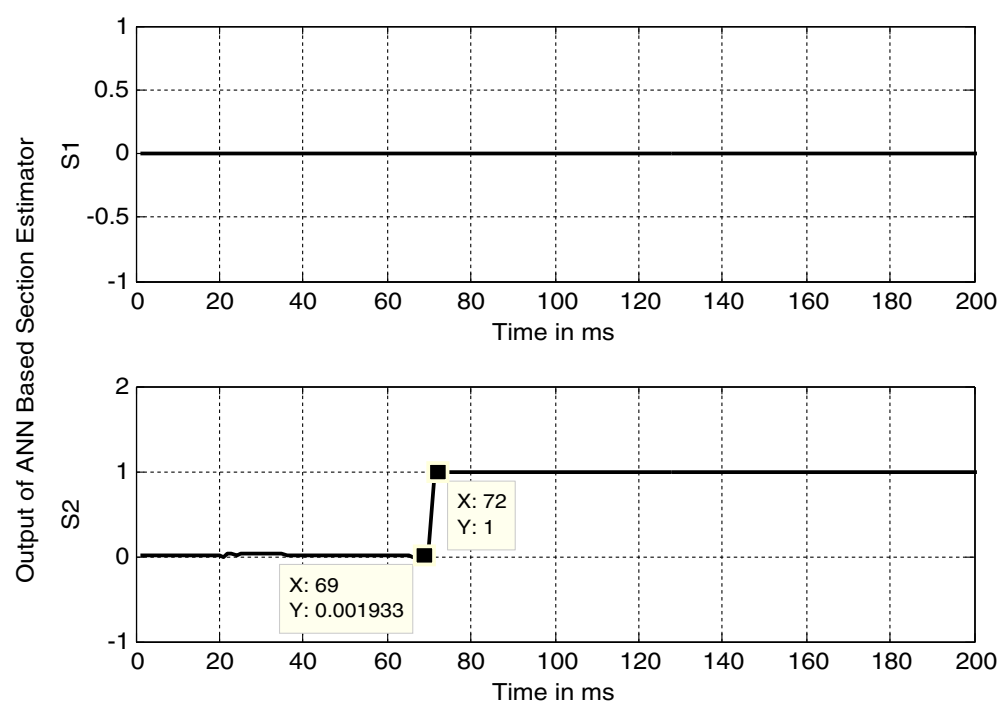

Fig. 10 Output of ANN based section estimator during AG fault at $150 \mathrm{~km}$ in Section-2 with $R_{f}=0 \Omega, \phi i=135^{\circ}$ at $60 \mathrm{~ms}$ time

\section{Impact of fault inception angle}

Fault may occur at any instant of time in transmission system. So it is important that the designed scheme should work for the entire fault inception angle variation. For testing the effectiveness of method, fault inception angles between $0^{\circ}-315^{\circ}$ in step of $45^{\circ}$ were selected by keeping the fault resistance fixed at $0 \Omega$. Some of the test results were shown in Table 7 for several inception angles of fault cases that substantiate the aptness of this current method for varied fault inception angles. Figure 10 shows the test results of the proposed scheme during AG fault at $150 \mathrm{~km}$ in Section-2 with $R_{f}=0 \Omega$, $\phi \mathrm{i}=135^{\circ}$ at $60 \mathrm{~ms}$ time.

\section{Response of reverse fault in section-1}

The performance evaluation of the proposed relay for faults in the reverse direction from the relay has been carried out which was located at bus-2, that is, in S1 and outcomes were presented in Table 8 and Fig. 11. As the fault locations are reverse faults from bus-2, so represented as negative. The relay requires maximum $4 \mathrm{~ms}$ for detecting the reverse fault. The proposed method is capable of detecting the reverse fault within quarter cycle of time.

Performance during variation in impedance of the source Impedance of the source determines the strength of the source, if the impedance of the source is low, it is a strong source and if it is high it is a weak source. The impedance of the source connected to either side of the transmission lines is varied to check the performance of the proposed scheme under variation in impedance of the source. The impedance of the source is varied and different types of fault at different location are tested and few test results are depicted in Table 9. From the results, it can be seen that, the fault detection time is increases in some cases up to half cycle time however it correctly identifies the fault type and its section. Thus it is confirmed that the proposed relaying scheme is not affected by variation in the source impedance and it can detect the faulty phase and its section within half cycle time.

\section{Test results of real time fault events}

In this section, two case studies were interpreted by considering real time fault event data. We have collected data from $400 \mathrm{kV}$ sub-station of PGCIL, Raipur, Chhattisgarh of two fault events occurred on

Table 8 Test results for reverse faults in section-1

\begin{tabular}{llll}
\hline Fault location $(\mathrm{km})$ & Fault type & $\begin{array}{l}\text { Fault detection } \\
\text { time }(\mathrm{ms})\end{array}$ & $\begin{array}{l}\text { Relay operation } \\
\text { time }(\mathrm{ms})\end{array}$ \\
\hline-16 & BCG & 63 & 3 \\
-15 & AG & 64 & 4 \\
-14 & AG & 62 & 2 \\
-13 & ABG & 63 & 3 \\
-12 & ACG & 63 & 3 \\
-11 & BCG & 63 & 3 \\
\hline
\end{tabular}




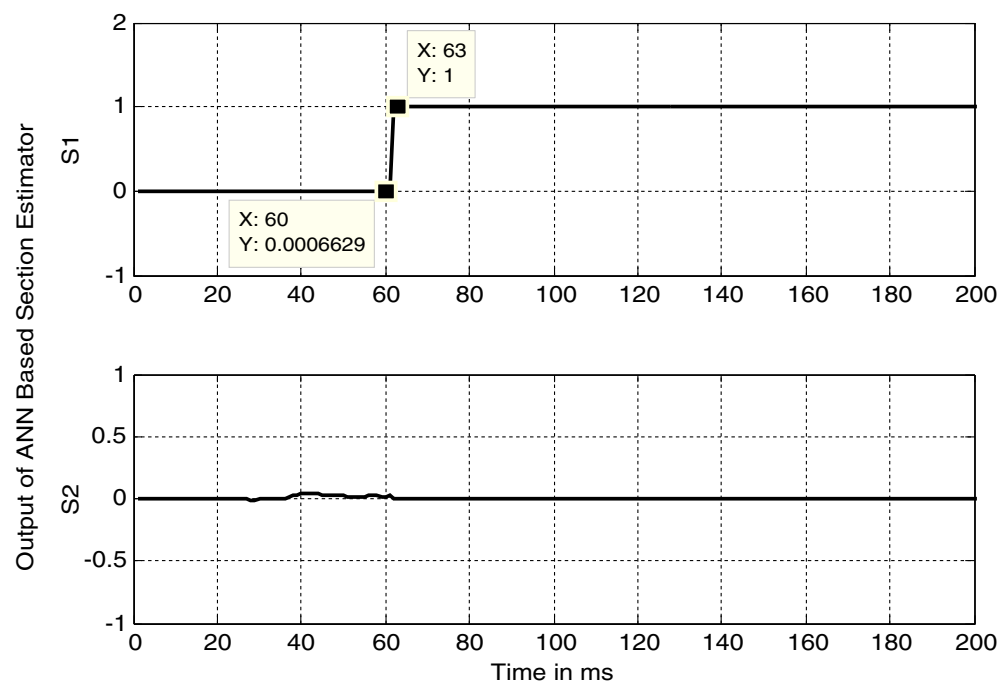

Fig. 11 Output of ANN based section estimator during BCG fault at $-16 \mathrm{~km}$ in Section- 1 with $R_{f}=0 \Omega, \phi i=0^{0}$, at 60 ms time

$22^{\text {nd }}$ July 2014 and $24^{\text {th }}$ April 2015 in $220 \mathrm{~km}$ line between Raipur-Korba. These data were preprocessed, and tested by applying the proposed ANN based fault detection, section estimation and fault classification schemes. The real time fault events case studies are discussed in detail in the following sub-sections.

\section{Case Study1: Real time fault event occurred on $22^{\text {nd }}$ July 2014}

After pre-processing the fault data, the fundamental components of 3- phase currents and voltages are depicted in Fig. 12. Before the inception of fault, all the outputs of the fault detector and classifier are low (zero) and after some time of occurrence the fault, the outputs of ANN based classifier in the phase "A" and ground
"G" goes high at $294 \mathrm{~ms}$ and $293 \mathrm{~ms}$ time rspectively and other outputs remains low (zero) and unaffected as exemplified in Fig. 13. The fault type is classified as LG fault (AG).

The operating time of relay can be calculated as follows:

Fault inception time $=291 \mathrm{~ms}$

Fault detection time (Maximum) of phase

$$
\mathrm{A}=294 \mathrm{~ms}
$$

Hence the time required by ANN based relay $=(294-291) \mathrm{ms}=3 \mathrm{~ms}(<$ Quarter cycle time $)$

Table 9 Response for variation in source impedance

\begin{tabular}{|c|c|c|c|c|c|c|c|c|}
\hline \multirow[t]{2}{*}{ Fault type } & \multirow{2}{*}{$\begin{array}{l}\text { Fault inception } \\
\text { angle(deg) }\end{array}$} & \multirow{2}{*}{$\begin{array}{l}\text { Source } \\
\text { Impedance } \\
\text { (in } \Omega \text { ) }\end{array}$} & \multirow{2}{*}{$\begin{array}{l}\text { Fault location } \\
\text { (in km) }\end{array}$} & \multicolumn{4}{|c|}{ Fault phase identification time(ms) } & \multirow{2}{*}{$\begin{array}{l}\text { Fault section } \\
\text { identification } \\
\text { time }\end{array}$} \\
\hline & & & & $\bar{A}$ & $B$ & C & $G$ & \\
\hline $\mathrm{AG}$ & 0 & $3.9+j 39.33$ & 10 & 2 & & & 2 & 2 \\
\hline BG & 45 & $4.1+j 41.20$ & 30 & - & 7 & - & 5 & 7 \\
\hline CG & 90 & $4.3+j 43.07$ & 50 & - & - & 3 & 2 & 3 \\
\hline$A B G$ & 135 & $4.9+j 44.89$ & 70 & 4 & 4 & - & 2 & 4 \\
\hline ACG & 180 & $3.9+j 35.53$ & 90 & 1 & - & 1 & 4 & 4 \\
\hline BCG & 225 & $3.7+j 33.66$ & 110 & - & 7 & 4 & 5 & 7 \\
\hline$B C$ & 270 & $2.8+j 31.86$ & 130 & - & 4 & 5 & - & 5 \\
\hline$C A$ & 315 & $2.7+j 29.98$ & 150 & 8 & & 8 & - & 8 \\
\hline$A B$ & 360 & $3.7+j 41.24$ & 170 & 3 & 5 & - & - & 5 \\
\hline$A B C$ & 0 & $5.3+j 42.97$ & 190 & 4 & 6 & 9 & & 9 \\
\hline
\end{tabular}



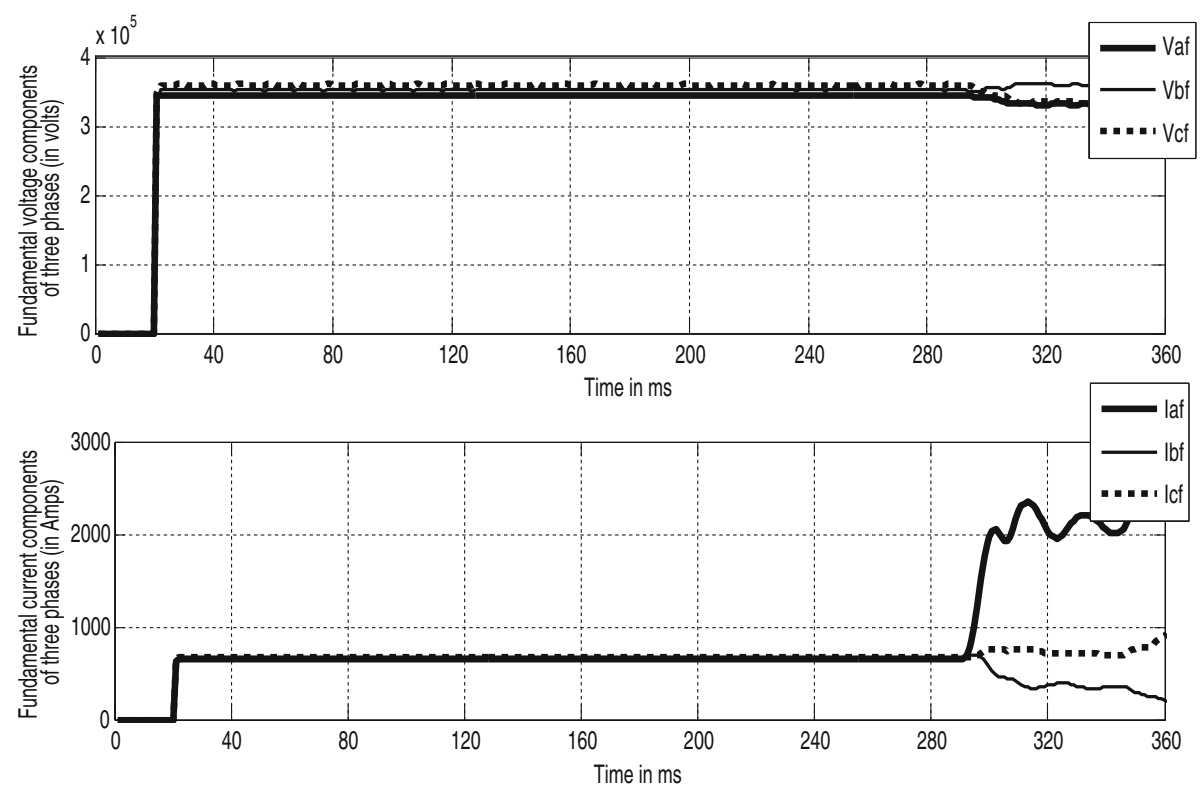

Fig. 12 Fundamental current and voltage waveforms in case of real time fault event occurred on $22^{\text {nd }}$ July 2014

\section{Case study2: real time fault event occurred on \\ $24^{\text {th }}$ April 2014}

The Fig. 14 shows the fundamental components of 3phase currents and voltages during a real time fault event on $24^{\text {th }}$ April 2014. In this cases also, after the fault occurrence, based on the response time of the proposed scheme as shown in Fig. 15, the output of ANN based fault classifier in phase "A" goes high at $294 \mathrm{~ms}$ time and ground " $G$ " becomes high at $293 \mathrm{~ms}$ time and other outputs remains low and unaffected. Thus this real time fault event is also classified as single line to ground fault in " $\mathrm{A}$ " phase. The relay operating time can be computed as follows:

Fault inception time $=287 \mathrm{~ms}$

Fault detection time (Maximum) of phase

$$
\mathrm{A}=294 \mathrm{~ms}
$$

Hence the time required by $\mathrm{ANN}$ based relay $=(294-287) \mathrm{ms}=7 \mathrm{~ms}(<$ Half cycle time $)$
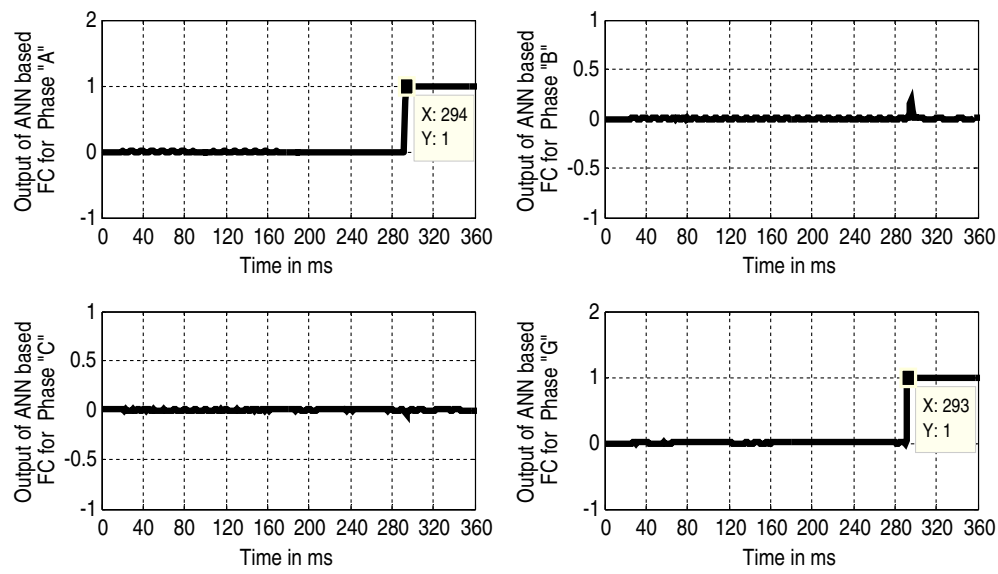

Fig. 13 Output of ANN based Fault Classifier during AG fault in case of real time fault event occurred on $22^{\text {nd }}$ July 2014 

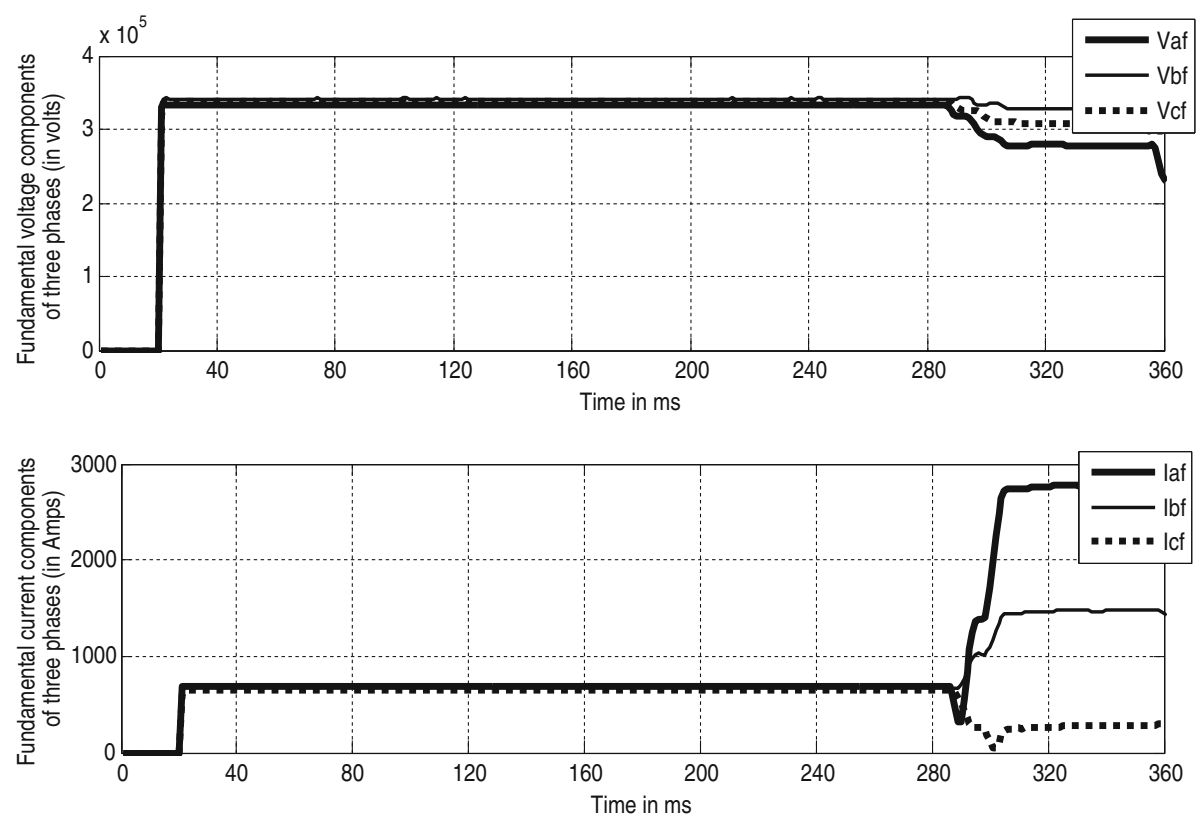

Fig. 14 Fundamental current and voltage waveforms in case of real time fault event occurred on $24^{\text {th }}$ April 2015

\section{Conclusion}

This paper proposes an ANN based fault detection, section identification (direction discrimination), fault classification and faulty phase selection schemes which consider the fundamental components of current and voltage signals of 3-phase as input. Proposed ANN based method was tested with huge number of fault cases by varying different fault parameters. Test results shows that proposed relaying schemes can provide primary as well as back-up protection to the forward and reverse line sections respectively. Reach setting of the relay is $99.5 \%$ and fault detection time is half cycle in most of the cases. As speed of the relay is an important criterion in directional relaying, proposed ANN based method will be efficient to use. The results based on extensive study indicate that the proposed scheme can reliably protect the transmission line against different fault situations and thus, is a potential candidate for effective protection measure. Moreover, the proposed scheme correctly identifies the faulty section and its direction when tested with real time fault events. Thus it can be implemented for protection of real power system networks as well.
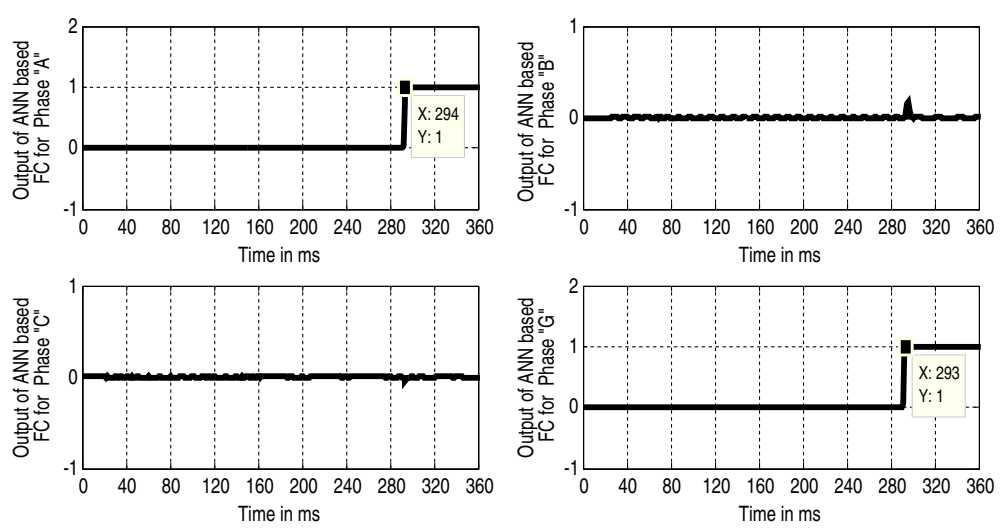

Fig. 15 Output of ANN based Fault Classifier during AG fault in case of real time fault event occurred on $24^{\text {th }}$ April 2015 


\section{Acknowledgment}

The authors acknowledge the financial support of Chhattisgarh Council of Science \& Technology (CGCOST), Raipur for funding the project No. 8062/ CGCOST/MRP/13, dtd. 27.12.2013. We also thank to the Department of Electrical Engineering, National institute of Technology, Raipur for providing the research facilities to conduct this project.

\section{Authors' contributions}

The first authors is principal investigator of the sponsored research project from Chhattisgarh Council of Science \& Technology (CGCOST), Raipur for funding the project No. 8062/CGCOST/MRP/13, dtd. 27.12.2013. The second author is the project fellow appointed for carrying out the simulation of different fault events in the C.G. power system network. First author has designed the ANN model which involves selection of ANN architecture, training of the ANN and thereafter testing with the simulated as well as the real time fault event collected from state power utility. Finally the paper has been written by all the authors collectively. All authors read and approved the final manuscript.

\section{Competing interests}

The authors declare that they have no competing interests.

Received: 26 May 2016 Accepted: 16 November 2016 Published online: 25 November 2016

\section{References}

1. Yadav, A., \& Dash, Y. (2014). An overview of transmission line protection by artificial neural network: fault detection, fault classification, fault location, and fault direction discrimination. Advances in Artificial Neural Systems. Article ID 230382, vol. 2014, pp. 20.

2. Phadke, A. G., \& Thorp, J. S. (1988). Computer Relaying for Power Systems. 2nd edn, New York: Wiley, 5, 137-186

3. Ziegler. (2006). Numerical distance protection principles and applications. SIEMENS. 2nd edn, Wiley, 3, 130-190.

4. Dalstein, T., \& Kulicke, B. (1995). Neural network approach to fault classification for high speed protective relaying. IEEE Transactions on Power Delivery, 10, 1002-1011.

5. Bo, Z. Q., Aggarwal, R. K., Johns, A. T., Li, H. Y., \& Song, Y. H. (1997). A new approach to phase selection using fault generated high frequency noise and neural networks. IEEE Transactions on Power Delivery, 12, 106-115.

6. Dong, X., Kong, W., \& Cui, T. (2009). Fault classification and faulted-phase selection based on the initial current traveling wave. IEEE Transactions on Power Delivery, 24, 552-559.

7. Youssef, O. A. S. (2002). New algorithm to phase selection based on wavelet transforms. IEEE Transactions on Power Delivery, 17, 908-914.

8. Pradhan, A. K., Routray, A., Pati, S., \& Pradhan, D. K. (2004). Wavelet fuzzy combined approach for fault classification of a series-compensated transmission line. IEEE Transactions on Power Delivery, 19, 1612-1618.

9. Kezunovic, M., Rikalo, I., \& Sobajic, D. J. (1995). High-speed fault detection and classification with neural nets. Electric Power Systems Research, 34, 109-116.

10. Chowdhury, F. N., \& Aravena, J. L. (1998). A modular methodology for fast fault detection and classification in power systems. IEEE Trans. on Control Systems Technology, 6, 623-634

11. Agarwal, R. K., Xuan, Q. Y., Dunn, R. W., Johns, A. T., \& Bennett, A. (1999). A novel fault classification technique of double circuit lines based on a combined unsupervised/supervised neural network. IEEE Transactions on Power Delivery, 14, 1250-1256.

12. Lin, W. M., Yang, C. D., Lin, J. H., \& Tsay, M. T. (2001). A fault classification method by RBF neural network with OLS learning procedure. IEEE Transactions on Power Delivery, 16, 473-477.

13. Wang, H., \& Keerthipala, W. W. L. (1998). Fuzzy-Neuro approach to fault classification for transmission line protection. IEEE Transactions on Power Delivery, 13, 1093-1104

14. Dash, P. K., Pradhan, A. K., \& Panda, G. (2000). A novel fuzzy neural network based distance relaying scheme. IEEE Transactions on Power Delivery, 15, 902-907.

15. Vasilic, S., \& Kezunovic, M. (2005). Fuzzy ART neural network algorithm for classifying the power system faults. IEEE Transactions on Power Delivery, 20, 1306-1314.

16. Kamel, T. S., Hassan, M. A. M., \& El-Morshedy, A. (2009). Advanced distance protection scheme for long Transmission lines in Electric Power systems using multiple classified ANFIS networks. In Proc. 5th International Conference on Soft Computing, Computing with Words and Perceptions in System Analysis, Decision and Control (pp. 1-5).

17. Silva, K. M., Souza, B. A. \& Brito, N. S. D. (2006). Fault detection and classification in transmission lines based on wavelet transform and ANN. IEEE Transactions on Power Delivery, 21, 2058-2063.

18. Mahanty, R. N., \& Dutta Gupta, P. B. (2006). Comparison of fault classification methods based on wavelet analysis and ANN. Electric Power Components and Systems, 34, 47-60.

19. Jamil, M., Kalam, A., Ansari, A. Q., \& Rizwan, M. (2014). Generalized neural network and wavelet transform based approach for fault location estimation of a transmission line. Applied Soft Computing, 19, 322-332.

20. Jain, A., Thoke, A. S., \& Patel, R. N. (2008). Fault classification of double circuit transmission line using artificial neural network. International Journal of Electrical Systems Science and Engineering, WASET, USA, 1, 230-235.

21. He, Z., Lin, S., Deng, Y., Li, X., \& Qian, Q. (2014). A rough membership neural network approach for fault classification in transmission lines. International Journal of Electrical Power and Energy Systems, 61, 429-439.

22. Coury, D. V., Oleskovicz, M., \& Aggarwal, R. K. (2002). An ANN routine for fault detection, classification and location in transmission lines. Electrical Power Components and Systems, 30, 1137-1149.

23. Gracia, J., Mazon, A. J., \& Zamora, I. (2005). Best ANN structures for fault location in single-and double-circuit transmission lines. IEEE Transactions on Power Delivery, 20, 2389-2395.

24. Jiang, J. A., Chuang, C. L., Wang, Y. C., Hung, C. H., Wang, J. Y., Lee, C. H., \& Hsiao, Y. T. (2011). A hybrid framework for fault detection, classification, and location- Part II: implementation and test results. IEEE Transactions on Power Delivery, 26, 1999-2008.

25. Yadav, A. (2012). Comparison of single and modular ANN based fault detector and classifier for double circuit transmission lines. International Journal of Engineering, Science and Technology, 4, 122-136.

26. Coury, D. V., \& Jorge, D. C. (1998). Artificial neural network approach to distance protection of transmission lines. IEEE Transaction on Power Delivery, 13, 102-108.

27. Khaparde, S. A., Warke, N., \& Agarwal, S. H. (1996). An adaptive approach in distance protection using an artificial neural network. Electric Power Systems Research, 37, 39-46.

28. Mazon, A. J., Zamora, I., Minambres, J. F., Zorrozua, M. A., Barandiaran, J. J., \& Sagastabeitia, K. (2000). A new approach to fault location in two-terminal transmission lines using artificial neural networks. Electric Power Systems Research Journal, 56, 261-266.

29. Yadav, A., \& Swetapadma, A. (2015). A single ended directional fault section identifier and fault locator for double circuit transmission lines using combined wavelet and ANN approach. International Journal of Electrical Power and Energy Systems, 69, 27-33.

30. Jongepier, A. G., \& van der Sluis, L. (1994). Adaptive distance protection of a double-circuit line. IEEE Transaction on Power Delivery, 9, 1289-1297.

31. Martins, L. S., Martins, J. F., Piers, V. F., \& Alegria, C. M. (2005). A neural space vector fault location for parallel double-circuit distribution lines. Electrical Power and Energy Systems Journal, 27, 225-231.

32. Skok, S., Marusic, A., Tesnjak, S., \& Pevik, L. (2002). Double-circuit line adaptive protection based on kohonen neural network considering different operation and switching modes. Large Engineering Systems Conference on Power Engineering, 2, 153-157.

33. Bhalja, B. R., \& Maheswari, R. P. (2007). High resistance faults on two terminal parallel transmission line: analysis, simulation studies, and an adaptive distance relaying scheme. IEEE Transaction on Power Delivery, 22, 801-812.

34. Oonsivilai, A., \& Saichoomdee, S. (2009). Distance transmission line protection based on radial basis function neural network. World Academy of Science, Engineering and Technology, 3, 75-78.

35. Jiang, J. A., Yang, J. Z., Lin, Y. H., Liu, C. W., \& Ma, J. C. (2000). An adaptive PMU based fault detection/location technique for transmission lines- Part l: Theory and algorithms. IEEE Transaction on Power Delivery, 15, 486-493.

36. Jiang, J. A., Lin, Y. H., Yang, J. Z., Too, T. M., \& Liu, C. W. (2000). An adaptive PMU based fault detection/location technique for transmission lines- Part II: PMU implementation and performance evaluation. IEEE Transaction on Power Delivery, 15, 1136-1146.

37. Sidhu, T. S., Singh, H., \& Sachdev, M. S. (1997). An artificial neural network for directional comparison relaying of transmission lines. In Proc. 6th International Conference on Developments in Power System Protection (pp. 282-285). 
38. Gang, W., Jiali, H., Yao, L., Xiaodan, Y., \& Zhongpu, L. (1997). Neural network application in directional comparison carrier protection of EHV transmission lines. In Proc. 4th International Conference on Advances in Power System Control, Operation and Management (Vol. 1, pp. 89-94).

39. Santos, R. C. D., \& Senger, E. C. (2011). Transmission lines distance protection using artificial neural networks. International Journal of Electrical Power and Energy Systems, 33, 721-730.

\section{Submit your manuscript to a SpringerOpen ${ }^{\circ}$ journal and benefit from:}

- Convenient online submission

- Rigorous peer review

- Immediate publication on acceptance

- Open access: articles freely available online

- High visibility within the field

- Retaining the copyright to your article

Submit your next manuscript at $>$ springeropen.com 